\title{
Glutathione S-transferase P1 (GSTP1) directly influences platinum drug chemosensitivity in ovarian tumour cell lines
}

\author{
L Sawers ${ }^{1}$, M J Ferguson ${ }^{2}$, B R Ihrig ${ }^{1}$, H C Young ${ }^{1}$, P Chakravarty ${ }^{3}$, C R Wolf ${ }^{1,4}$ and G Smith ${ }^{*}, 1$ \\ ${ }^{1}$ Division of Cancer Research, Medical Research Institute, University of Dundee, Ninewells Hospital and Medical School, Dundee \\ DD1 9SY, UK; ${ }^{2}$ Dundee Cancer Centre, NHS Tayside, Ninewells Hospital and Medical School, Dundee DD1 9SY, UK; \\ ${ }^{3}$ Bioinformatics and Biostatistics Service, Cancer Research UK, 44 Lincolns Inn Fields, London WC2A 3PX, London, UK and ${ }^{4}$ Cancer \\ Research UK Molecular Pharmacology Unit, Division of Cancer Research, Medical Research Institute, Ninewells Hospital and \\ Medical School, Dundee DD1 9SY, UK
}

Background: Chemotherapy response in ovarian cancer patients is frequently compromised by drug resistance, possibly due to altered drug metabolism. Platinum drugs are metabolised by glutathione S-transferase P1 (GSTP1), which is abundantly, but variably expressed in ovarian tumours. We have created novel ovarian tumour cell line models to investigate the extent to which differential GSTP1 expression influences chemosensitivity.

Methods: Glutathione S-transferase P1 was stably deleted in A2780 and expression significantly reduced in cisplatin-resistant A2780DPP cells using Mission shRNA constructs, and MTT assays used to compare chemosensitivity to chemotherapy drugs used to treat ovarian cancer. Differentially expressed genes in GSTP1 knockdown cells were identified by Illumina HT-12 expression arrays and qRT-PCR analysis, and altered pathways predicted by MetaCore (GeneGo) analysis. Cell cycle changes were assessed by FACS analysis of PI-labelled cells and invasion and migration compared in quantitative Boyden chamber-based assays.

Results: Glutathione S-transferase P1 knockdown selectively influenced cisplatin and carboplatin chemosensitivity (2.3- and 4.83fold change in $\mathrm{IC}_{50}$, respectively). Cell cycle progression was unaffected, but cell invasion and migration was significantly reduced. We identified several novel GSTP1 target genes and candidate platinum chemotherapy response biomarkers.

Conclusions: Glutathione S-transferase P1 has an important role in cisplatin and carboplatin metabolism in ovarian cancer cells. Inter-tumour differences in GSTP1 expression may therefore influence response to platinum-based chemotherapy in ovarian cancer patients.

Ovarian cancer often presents at an advanced stage where treatment is rarely curative (Kristensen and Trope, 1997). Chemotherapy with platinum-based drug regimens (combining cisplatin or carboplatin with paclitaxel) can be initially effective, but longer-term treatment is frequently compromised by the development of drug-resistant disease (Vaughan et al, 2011). Platinum drugs are thought to act by promoting the formation of intra-strand DNA crosslinks, thus inhibiting DNA translation and replication (Eastman, 1987). Although several candidate drug resistance mechanisms, including impaired DNA repair, decreased drug uptake, increased drug efflux and detoxification, have been proposed (reviewed by Galluzzi et al, 2012), we are still some way from understanding the molecular basis of drug resistance, and from developing biomarkers to predict the onset and monitor the development of drug-resistant disease in cancer patients.

In recent work, we used qRT-PCR analysis to quantify intertumour differences in the expression of multiple candidate genes associated with disease progression and chemotherapy response in ovarian tumours (Smith et al, 2012). One of the most abundantly expressed genes in ovarian tumours and tumour cell lines was

*Correspondence: Dr G Smith; E-mail: g.smith@dundee.ac.uk

Received 7 May 2014; revised 11 June 2014; accepted 18 June 2014; published online 10 July 2014

(c) 2014 Cancer Research UK. All rights reserved 0007-0920/14 
glutathione S-transferase P1 (GSTP1, EC 2.5.1.18), a polymorphic phase II drug-metabolising enzyme, which conjugates the antioxidant tri-peptide glutathione with many toxic hydrophobic and electrophilic xenobiotics to facilitate elimination (reviewed by Hayes and Pulford, 1995). Increased GSTP1 expression has been reported in pre-neoplastic lesions in chemically induced animal cancer models (Satoh et al, 1985) and in many human tumours, relative to surrounding normal tissues (Shea et al, 1988). Although a useful neoplasia biomarker, it is not known whether increased GSTP1 expression directly influences carcinogenesis, or is simply a bystander effect, where expression of this highly inducible gene is increased as part of the adaptive response mounted by the neoplastic cell. In support of a direct role in carcinogenesis, however, GSTP1 inhibits the stress-inducible c-Jun N-terminal kinase $(J N K)$ in vitro, and JNK activity is reduced in GSTP1 null mice (Adler et al, 1999; Yin et al, 2000; Elsby et al, 2003). Additional roles for GSTP1 in the regulation of genes including TRAF2 (Wu et al, 2006), CDK5 (Sun et al, 2011) and the FAS death receptor (Anathy et al, 2012) have also been described.

Purified GSTP1 conjugates cisplatin in vitro (Hagrman et al, 2004), and GSTP1 expression is increased in human tumour cell lines either inherently or made resistant to chemotherapy drugs including cisplatin and various alkylating agents (Black and Wolf, 1991; McLellan and Wolf, 1999), although a direct association linking differential glutathione conjugation with platinum drug resistance in human ovarian tumours has not been convincingly demonstrated. In support of a functional association, heterologous GSTP1 expression in Saccharomyces cerevisiae (Black et al, 1990) or of various GSTP1 alleles in Escherichia Coli influenced sensitivity to platinum and additional chemotherapy drugs (Ishimoto and Ali-Osman, 2002). In contrast, similar experiments in breast cancer MCF7 cells revealed only modest effects on platinum sensitivity (Peklak-Scott et al, 2008), while partial GSTP1 knockdown in the adriamycin-resistant human colorectal cancer cell line M7609 increased sensitivity not only to the selection agent, but to cisplatin, melphalan and etoposide (Ban et al, 1996).

We therefore created novel ovarian tumour cell line models in which GSTP1 expression is stably deleted, to investigate whether differential GSTP1 expression directly influenced chemosensitivity to platinum drugs, and to other drugs routinely used in the treatment of ovarian cancer patients. We have used whole-genome transcriptional profiling analysis and various quantitative phenotypic assays to identify gene expression and associated phenotypic differences in parental and GSTP1 knockdown cell lines.

\section{MATERIALS AND METHODS}

Ovarian tumour cell lines. A2780 and cisplatin-resistant derivative A2780DPP cells were obtained from ATCC (LGC Standards, Teddington, UK), via Cancer Research UK Cell Services. A2780 cells were maintained in RPMI-1640 media supplemented with $10 \%$ FBS, and A2780DPP cells (derived in vitro following longterm cisplatin selection; Behrens et al, 1987) in RPMI-1640 media supplemented with $15 \% \mathrm{FBS}$ and $1 \mu \mathrm{M}$ cisplatin. Both cell lines were maintained in $37^{\circ} \mathrm{C}$ incubators, supplemented with $5 \% \mathrm{CO}_{2}$.

Creation and characterisation of stable GSTP1 knockdown cell lines. Glutathione $S$-transferase P1 expression was stably knockeddown in A2780 and expression significantly reduced in A2780DPP cells by RNA interference using Mission shRNA plasmids (SigmaAldrich, Gillingham, UK). Five unique GSTP1-specific shRNA plasmids (clones TRCN0000083773, TRCN0000083774, TRCN000 0083775, TRCN0000083776 and TRCN0000083777) and a negative control plasmid (empty vector control, SHC001) were purchased as glycerol stocks and plasmid DNA extracted using plasmid DNA maxi prep kits (Qiagen, Manchester, UK) according to the manufacturer's instructions. A2780 and A2780DPP cells $\left(2.5 \times 10^{5}\right.$ cells per well in six-well plates) were transfected with each plasmid using lipofectamine (Life Technologies, Paisley, UK), and shRNAcontaining cells selected with puromycin. Individual cell colonies were picked using cloning cylinders, harvested for mRNA analysis (A2780DPP cells) or expanded to $75 \mathrm{~cm}^{2}$ tissue culture flasks and harvested for mRNA and protein analysis (A2780 cells). GSTP1 knockdown in A2780 cells was confirmed by qRT-PCR analysis and western blotting, and by qRT-PCR analysis in A2780DPP cells. Cell growth rates were compared by plating $1 \times 10^{5}$ cells from each cell line in individual wells of six-well dishes (day 0). Cells were harvested daily by trypsinisation (days 2-10) and counted using a haemocytometer.

RNA extraction and qRT-PCR analysis. Cells were grown to $80 \%$ confluency in $75 \mathrm{~cm}^{2}$ flasks, harvested by trypsinisation, counted using a haemocytometer, and $1 \times 10^{7}$ cells used for RNA extraction using a Qiagen RNeasy mini kit (Qiagen), following the manufacturer's protocol for mammalian cells, with additional on column DNAse digestion (RNAse free DNAse kit, Qiagen). RNA yield and integrity were initially assessed from absorbance readings at 260 and $280 \mathrm{~nm}$ using a Nanodrop 1000 spectrophotometer (Thermo Fisher Scientific, Loughborough, UK), and confirmed using an Agilent Bioanalyzer 2100 and RNA 6000 Nano LabChip Kit (Agilent Technologies, Wokingham, UK) according to the manufacturer's guidelines.

RNA was reverse transcribed into cDNA (50 ng RNA per $20 \mu \mathrm{l}$ RT reaction) using High Capacity RNA to cDNA kits (Life Technologies) according to the manufacturer's instructions, and the expression of GSTP1 (Taqman probe ID Hs00168310_m1) and the loading control 18S ribosomal RNA (Hs03003631_g1) assessed by qRT-PCR analysis, as previously described (Smith et al, 2012), where $20 \mu$ l individual reaction mixes (per well) contained $10 \mu \mathrm{l}$ Taqman Universal PCR Master Mix (Life Technologies), $1 \mu$ l genespecific Taqman probe, $1 \mu \mathrm{l} \mathrm{cDNA}$ and $8 \mu \mathrm{l}$ sterile water. Each reaction was performed in triplicate and run on the Standard RealTime PCR program on a 7900 Taqman real-time PCR system (Applied Biosystems, Warrington, UK) using pre-defined thermal cycling conditions $\left(50{ }^{\circ} \mathrm{C}\right.$ for $2 \mathrm{~min}, 94.5^{\circ} \mathrm{C}$ for $10 \mathrm{~min}, 40$ cycles of $\left(97^{\circ} \mathrm{C}\right.$ for $30 \mathrm{~s}$ and $59^{\circ} \mathrm{C}$ for $\left.1 \mathrm{~min}\right)$ ). Similarly, the expression of ALX1 (Hs00232518_m1), CDH2 (Hs00983056_m1), FOXC1 (Hs00559473_s1), LAYN (Hs00379511_m1), TM4SF (Hs00371661_m1) and VCAN (Hs00171642_m1) was additionally investigated by qRT-PCR analysis in A2780 and A2780/GSTP1 cells. Analysis was performed using SDS 2.3 software (Applied Biosystems); optimal experimental baselines and thresholds were chosen for each gene, and gene expression quantitated by cycle threshold $(\mathrm{Ct})$ values. Relative expression values were determined by comparing the expression of each target gene with the invariant 'loading control' $18 S$ ribosomal RNA, as previously described (Smith et al, 2012). All samples were analysed in triplicate and gene expression calculated relative to $18 \mathrm{~S}$ ribosomal RNA \pm compound error $\left((\text { s.d. target gene })^{2}+(\text { s.d. } 18 \mathrm{~S} \text { ribosomal RNA })^{2}\right)^{1 / 2}$, where s.d. = standard deviation of the mean of triplicate replicates.

Whole-genome microarray mRNA analysis in A2780 and A2780/GSTP1 cells. RNA was prepared from A2780 and A2780/GSTP1 cells and integrity assessed as described above. Each RNA sample was converted to biotinylated amplified cRNA using an Illumina TotalPrep RNA Amplification kit (Life Technologies) according to the manufacturer's guidelines, and cRNA quality and concentration confirmed on the Agilent Bioanalyzer 2100, as described above. cRNA samples were hybridised in triplicate on Illumina Human HT-12 BeadChip Arrays (Illumina, Little Chesterford, UK) using standard protocols optimised by the Genetics Core, Wellcome Trust Clinical Research Facility, University of Edinburgh. 
Bioinformatics analysis. Gene expression data were analysed using Bioconductor 2.7 (http://bioconductor.org), running on R 2.12.1. Normalised probeset expression measures were calculated using $\log _{2}$ transformation and quantile normalisation using the 'Lumi' package. To identify significant differences in gene expression in A2780 and A2780/GSTP1 cells, moderated Student's $t$-tests were performed using empirical Bayes statistics in the 'Limma' package, and resulting $P$-values adjusted for multiple testing using the false discovery rate (FDR) Benjamini and Hochberg method (Smyth, 2004); probe sets with adjusted $P$-value FDR $q<0.05$ were called differentially expressed. Differentially expressed probes were also subjected to Metacore Pathway analysis (Thomson Reuters, London, UK) to identify enrichment of pathways and processes, using hyper-geometric distributions to determine the most enriched gene sets (FDR $q<0.05$ ).

Protein expression and western blotting. Cells for protein extraction were plated in six-well dishes, cultured until confluent, growth media removed and washed with ice-cold PBS before lysis in $0.5 \mathrm{ml}$ RIPA buffer $(50 \mathrm{~mm}$ Tris- $\mathrm{HCl}, 150 \mathrm{~mm} \mathrm{NaCl}, 5 \mathrm{~mm}$ EDTA, $0.1 \%$ SDS, $0.5 \%$ sodium deoxycholate, $1 \%$ Nonidet P-40) supplemented with $2 \%$ protease inhibitor cocktail (Sigma-Aldrich). Lysed cells were centrifuged (13000 r.p.m; $10 \mathrm{~min}$ ) to pellet cell debris, and protein concentrations of the resulting cell supernatants determined by Bradford Assay (Bio-Rad, Hemel Hempstead, UK), relative to a standard curve prepared from serial dilutions of bovine serum albumin $\left(0-1 \mathrm{mg} \mathrm{ml}^{-1}\right)$, with absorbance readings at $595 \mathrm{~nm}$.

Glutathione $S$-transferase P1 expression was analysed in protein extracts from each cell line by western blotting, following SDSPAGE. Each protein sample $(40 \mu \mathrm{g})$ was diluted in equal volumes of $5 \times$ sample buffer (10\% SDS, $250 \mathrm{~mm}$ Tris-HCl ( $\mathrm{pH} 6.8)$, $1 \mathrm{mg} \mathrm{ml}^{-1}$ bromophenol blue, $0.5 \mathrm{M} \mathrm{DTT}, 50 \%$ glycerol), denatured and separated by SDS-PAGE using 12\% Mini-PROTEAN 3 polyacrylamide gels (Bio-Rad) in Tris-glycine buffer $(25 \mathrm{~mm}$ Tris $\mathrm{pH} 8.3,250 \mathrm{~mm}$ glycine, $0.1 \%$ SDS). Following electrophoresis, proteins were transferred to nitrocellulose membranes in Trisglycine-methanol buffer (48 mM Tris $\mathrm{pH} 8.3,39 \mathrm{~mm}$ glycine, $0.037 \%$ SDS, $10 \%$ methanol) and nonspecific antibody binding blocked by incubation for $2 \mathrm{~h}$ in TBST $(25 \mathrm{~mm}$ Tris- $\mathrm{HCl} \mathrm{pH} 7.6$, $150 \mathrm{~mm} \mathrm{NaCl}, 0.05 \%$ Tween-20) containing 5\% milk powder. Membranes were then incubated overnight with a rabbit polyclonal GSTP1 primary antibody ((Henderson et al, 1998), diluted $1: 1000)$ or a mouse monoclonal $\beta$-actin antibody (sc-47778, Santa Cruz Biotechnology Inc., Heidelberg, Germany, diluted $1: 1000$ ), washed in PBST (PBS supplemented with $0.05 \%$ Tween-20) and incubated for $1 \mathrm{~h}$ with a swine anti-rabbit polyclonal secondary antibody (Dako PO399, diluted 1:1000, GSTP1, Dako, Ely, UK) or goat anti-mouse polyclonal secondary antibody (Dako PO447, diluted $1: 1000, \beta$-actin). Immunoblots were developed using an ECLchemiluminescence kit (Merck Millipore, Watford, UK) according to the manufacturer's instructions.

Analysis of cellular glutathione levels. Total cellular glutathione (GSSG + GSH) levels were compared in A2780 and A2780/GSTP1 cells using a Glutathione Assay kit (Sigma-Aldrich) according to the manufacturer's guidelines. Cells were harvested, washed in PBS, counted using a haemocytometer and re-suspended to a final concentration of $1 \times 10^{8}$ cells ml $^{-1}$ in PBS. Cells were then pelleted, de-proteinised with 5\% 5-sulfosalicyclic acid and glutathione levels assessed using a kinetic assay in which catalytically active glutathione reduces 5,5-dithiobis(2-nitrobenzoic acid) (DTNB) to 5-dithiobis(2-nitrobenzoic acid) (TNB). TNB production was measured spectrophotometrically at $412 \mathrm{~nm}$, with kinetic reads at 1-min intervals for $5 \mathrm{~min}$, and glutathione levels extrapolated from a standard curve of serial dilutions of reduced glutathione (positive values for both GSH and GSSG are obtained in the reaction).
Ovarian cell line chemosensitivity assays. MTT assays (Mosmann, 1983) were used to compare chemosensitivity of A2780 and A2780/GSTP1 cells to the GSTP1 model substrate ethacrynic acid and chemotherapy drugs cisplatin, carboplatin, paclitaxel, doxorubicin, topotecan and gemcitabine. Each cell line was plated in a 96-well plate (5000 cells per well) and treated in triplicate with serial dilutions of each drug. Ethacrynic acid was used at concentrations from 2.5 to $80 \mu \mathrm{M}$, and chemotherapy drugs at concentrations selected to mimic typical peak plasma levels in ovarian cancer patients (range $0-200 \%$ (peak plasma); cisplatin $0-25 \mu \mathrm{M}$, carboplatin $0-85 \mu \mathrm{M}$, paclitaxel $0-32 \mu \mathrm{M}$, doxorubicin $0-6 \mu \mathrm{M}$, gemcitabine $0-190 \mu \mathrm{M}$ and topotecan $0-56 \mu \mathrm{M}$; Konecny et al, 2000). Cells were drug treated for $72 \mathrm{~h}$, media removed and $100 \mu \mathrm{l}$ of a $0.5 \mathrm{mg} \mathrm{ml}^{-1}$ MTT solution (3-(4,5-dimethylthiazol-2-yl)2,5-diphenyltetrazolium bromide in phenol red-free DMEM) added and cells incubated at $37^{\circ} \mathrm{C}$ for $3 \mathrm{~h}$. The resulting formazan crystals were solubilised in DMSO, quantitated spectrophotometrically at $570 \mathrm{~nm}$ and the percentage of live cells remaining following each drug treatment calculated (assigning a value of $100 \%$ to vehicletreated cells). $\mathrm{IC}_{50}$ values were calculated from log dose-response curves using Prism 6 software (GraphPad Software Inc., La Jolla, CA, USA).

Cell invasion and migration assays. Cell invasion and migration was assessed using 24-well InnoCyte Cell Invasion and Migration Assays (Merck Millipore) according to the manufacturer's guidelines. Cell invasion was assessed by plating cells in serum-free medium in invasion chambers $(8 \mu \mathrm{m}$ membranes $)$ coated with basement membrane matrix, which prevents non-invasive cells from passing through the membrane pores. Similarly, cell migration was compared in A2780 and A2780/GSTP1 cells by plating each cell line in serum-free medium in migration chambers. In both assays, serum-containing medium was added to each well to induce cell migration, assessed by staining cells attached to the lower side of the membrane with the fluorescent cell permeable dye Calcein-AM, and measuring fluorescence at $485 \mathrm{~nm}$ (excitation) and $520 \mathrm{~nm}$ (emission). Negative control A2780 cells were additionally treated with the anti-migratory drug Latrunculin A.

FACS analysis. Cell cycle parameters were compared in A2780 and A2780/GSTP1 cells by flow cytometry following propidium iodide labelling of cell line DNA. Cells were untreated, or treated with $12.66 \mu \mathrm{M}$ cisplatin (to represent typical $100 \%$ patient peak plasma levels) for 1,4 or $24 \mathrm{~h}$ then fixed in ice-cold $70 \%$ ethanol overnight at $-20{ }^{\circ} \mathrm{C}$, re-suspended in PBS and stained by incubation with propidium iodide $\left(40 \mu \mathrm{g} \mathrm{ml}^{-1}\right.$, Sigma-Aldrich) and RNAse A $\left(100 \mu \mathrm{g} \mathrm{ml}^{-1}\right.$, Sigma-Aldrich) for $30 \mathrm{~min}$ at $37^{\circ} \mathrm{C}$ in the dark. Cell cycle parameters (10 000 cells per sample) were analysed using a FACScan flow cytometer (Becton Dickinson, Oxford, UK) and Cellquest Pro software to determine cell cycle phases and cells in sub- $\mathrm{G}_{\mathrm{o}} / \mathrm{G}_{1}$.

Statistical analysis. All statistical tests were performed using the SPSS statistics package version 20.0 (IBM, New York, NY, USA). Independent sample $t$-tests were used to assess differences in gene expression identified by qRT-PCR analysis and invasion and migration changes in A2780 and A2780/GSTP1 cells.

\section{RESULTS}

We previously showed that GSTP1 is abundantly expressed in human ovarian tumours, and highlighted marked inter-tumour differences in GSTP1 expression (Smith et al, 2012). To investigate whether individuality in GSTP1 expression influences chemotherapy response, we used shRNA-mediated gene silencing to stably knockdown GSTP1 in the ovarian tumour cell line A2780, created from a chemotherapy-naive ovarian cancer patient (Behrens et al, 
1987). A2780 cells were transfected with each of five GSTP1specific Mission shRNA pLKO.1-puro plasmids (773, 774, 775, 776 and 777) and a negative control plasmid as described in Materials and Methods section. Following lipofectamine selection, multiple antibiotic-resistant colonies were screened for GSTP1 knockdown
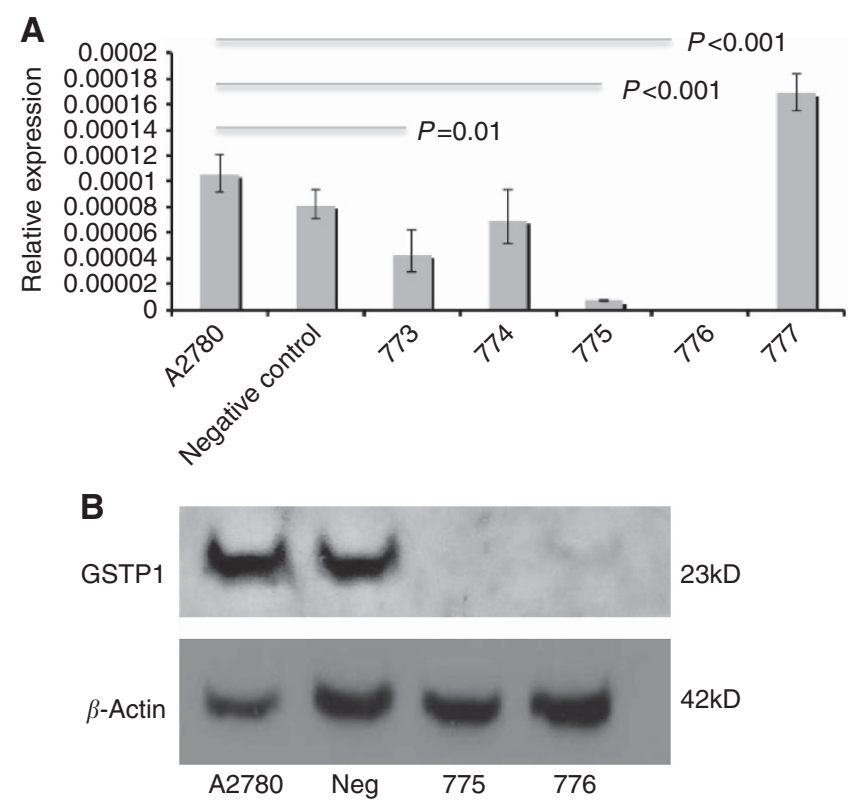

Figure 1. Generation of stable GSTP1 knockdown cell lines. A2780 ovarian tumour cells were transfected with various GSTP1 Mission shRNA constructs (clones 773, 774, 775, 776 and 777) and an empty vector negative control plasmid as described in Materials and Methods section. Following puromycin selection, GSTP1 expression was compared in A2780 cells and in each novel daughter cell line (A) by qRT-PCR analysis, relative to $18 \mathrm{~S}$ ribosomal RNA (significant differences in gene expression $(P<0.05)$ are highlighted) and $(\mathbf{B})$ by western blot analysis of clones 775 and 776 to confirm loss of GSTP1 protein expression.
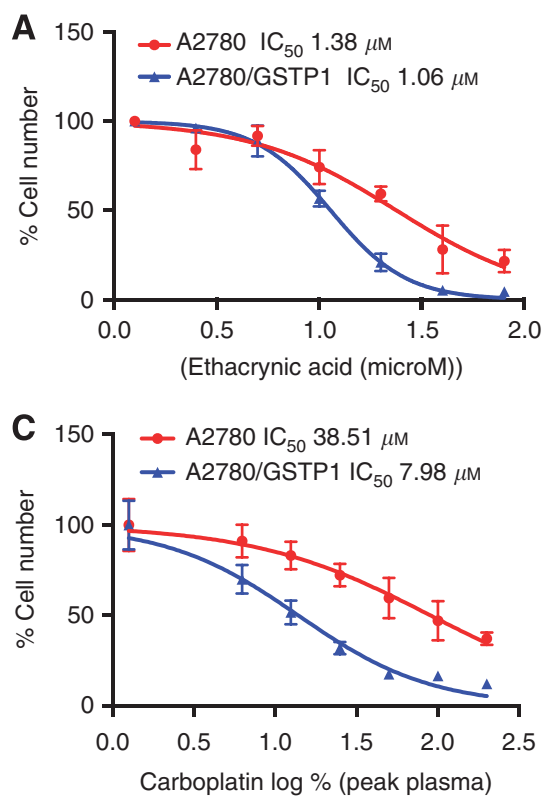

by $\mathrm{qRT}-\mathrm{PCR}$ analysis, and gene knockdown confirmed in cells transfected with plasmids 773,775 and 776 (Figure 1A), with maximum reduction in shRNA construct 775 and 776 -transfected cells. GSTP1 protein expression was evaluated by western blotting, with complete loss of GSTP1 expression confirmed in shRNA construct 775 -transfected cells and $>95 \%$ reduction in protein expression in construct 776-transfected cells (Figure 1B). GSTP1775 knockdown cells (A2780/GSTP1) were therefore selected for use in additional experiments, following additional confirmation of increased total cellular glutathione levels (A2780 83.16 $\pm 1.67 \mu \mathrm{M}$ and A2780/GSTP1 $116.85 \pm 4.67 \mu \mathrm{M})$, consistent with reduced GSTP1 catalytic activity.

MTT assays were then used to compare chemosensitivity of A2780 and A2780/GSTP1 cells to the diuretic and wellcharacterised GSTP1 substrate ethacrynic acid. GSTP1 conjugates and detoxifies ethacrynic acid (Ahokas et al, 1984), which was significantly more toxic to GSTP1 null cells (1.3-fold increase in $\mathrm{IC}_{50}, P=0.004$, Figure $2 \mathrm{~A}$ ). Sensitivity to platinum-based chemotherapy drugs was then compared in A2780 and A2780/GSTP1 cells and significant differences in chemosensitivity observed following treatment with cisplatin $\left(2.28\right.$-fold decrease in $\mathrm{IC}_{50}$, $P=0.03$, Figure $2 \mathrm{~B}$ ) and carboplatin (4.83-fold decrease in $\mathrm{IC}_{50}$, $P=0.007$, Figure $2 \mathrm{C}$ ), and a less pronounced decrease in sensitivity to paclitaxel (1.58-fold increase in $\mathrm{IC}_{50}, P=0.02$, Figure $2 \mathrm{D}$ ). Chemosensitivity to additional drugs used to treat ovarian cancer was also compared but no significant differences in $\mathrm{IC}_{50}$ values identified (doxorubicin $0.13 v s 0.11 \mu \mathrm{M}$, gemcitabine 3.32 ss $3.34 \mu \mathrm{M}$ and topotecan $1.00 v s 1.12 \mu \mathrm{M}$ in A2780 and A2780/GSTP1 cells, respectively (all $P$-values $>0.05)$ ). To confirm our findings, MTT assays were repeated in GSTP1-776 cells and very similar changes in cisplatin, carboplatin and paclitaxel chemosensitivity identified (data not shown).

As GSTP1 knockdown significantly increased cisplatin and carboplatin chemosensitivity in A2780 cells, we further investigated whether GSTP1 knockdown in the related platinum-resistant A2780DPP cell line (Behrens et al, 1987) could re-sensitise these drug-resistant cells to platinum-based chemotherapy. A2780DPP cells were therefore transfected with shRNA constructs 775 and 776, optimised for GSTP1 knockdown in the experiments described
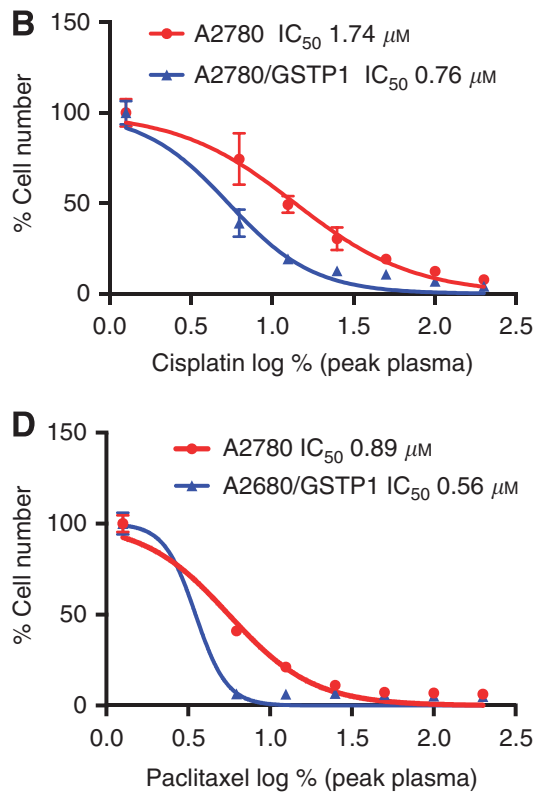

Figure 2. Chemosensitivity changes induced by stable GSTP1 knockdown in A2780 cells. MTT cytotoxicity assays were used to compare chemosensitivity to (A) ethacrynic acid, (B) cisplatin, (C) carboplatin and (D) paclitaxel in A2780 and A2780/GSTP1 cells as described in Materials and Methods section. Cisplatin, carboplatin and paclitaxel were used at doses representative of typical peak plasma levels in ovarian cancer patients. Each assay was performed in triplicate-mean data from three independent experimental replicates is illustrated. 
above. In contrast to drug-sensitive A2780 cells, however, although puromycin-resistant colonies were initially formed in A2780DPP cells in multiple replicate experiments, the colonies formed were relatively small (10-20 cells per colony) and were viable for only $48 \mathrm{~h}$ (Figure 3A). As our control transfections resulted in viable colony formation in both A2780 and A2780DPP cells, we hypothesised that GSTP1 knockdown may be lethal in A2780DPP cells, which are grown in medium containing $1 \mu \mathrm{M}$ cisplatin to maintain the drugresistant phenotype. To confirm GSTP1 knockdown in A2780DPP cells, we isolated individual puromycin-resistant colonies $24 \mathrm{~h}$ after colony formation using cloning cylinders, and extracted sufficient RNA to confirm GSTP1 knockdown by qRT-PCR analysis (Figure 3B). Unfortunately, we were unable to harvest sufficient A2780DPP/GSTP1 knockdown cells to perform western blotting, cytotoxicity assays or more detailed phenotypic characterisation, but our confirmation of GSTP1 knockdown, together with selective platinum toxicity in puromycin-resistant clones is consistent with an essential role for GSTP1 in glutathione conjugation and cisplatin detoxification. We further attempted to confirm this hypothesis by knocking down GSTP1 in A2780DPP cells grown in the absence of cisplatin selection, but found that control untransfected A2780DPP cells did not retain a stable drug-resistant phenotype over the 6-week experimental period in the absence of cisplatin selection (data not shown).
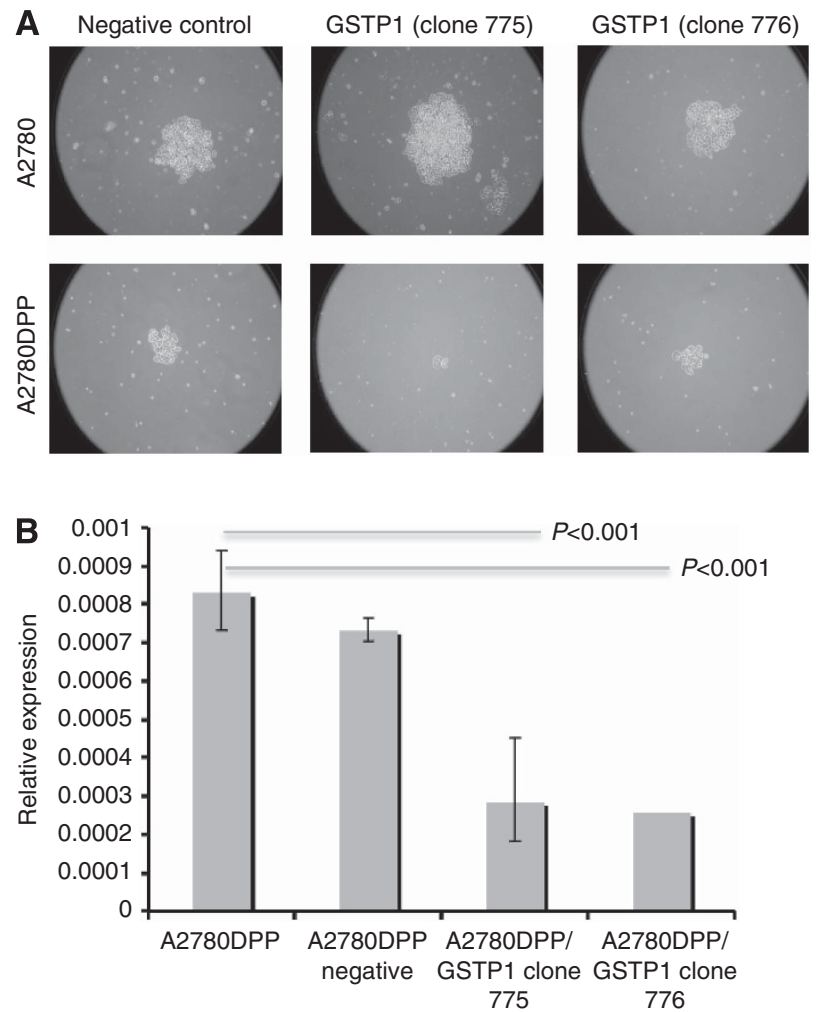

Figure 3. GSTP1 knockdown is toxic to cisplatin-resistant A2780DPP cells. A2780 and cisplatin-resistant A2780DPP cells were transfected with GSTP1 Mission shRNA plasmids 775 and 776 or an empty vector negative control plasmid, as described in Materials and Methods section, and GSTP1 knockdown cells identified by puromycin selection. (A) Viable puromycin-resistant colonies were obtained from all transfections in A2780 cells, but only from A2780DPP cells transfected with an empty vector negative control plasmid. (B) qRT-PCR analysis was used to confirm GSTP1 knockdown in A2780DPP cells (illustrated relative to the expression of $18 \mathrm{~S}$ ribosomal $R N A$ ) following transfection of GSTP1 shRNA clones. Cells from small colonies with limited viability were collected using cloning cylinders, and RNA extracted as described in Materials and Methods section.
To investigate the cellular phenotypes resulting from GSTP1 knockdown in A2780 cells, Illumina HT-12 Expression BeadChip Arrays were used to compare gene expression in A2780 and A2780/GSTP1 cells. Each HT-12 array contains $>47000$ unique probe sets, corresponding to $>28000$ coding transcripts; 2671 probes were significantly more highly expressed, and 2717 probes less highly expressed in A2780/GSTP1 cells. Of these, $\geqslant 2$-fold differences in gene expression were identified for 336 gene transcripts-the most significantly differentially expressed genes are summarised in Supplementary Table 1 (Supplementary Information), and changes in gene expression predicted by BeadChip Array analysis confirmed by qRT-PCR analysis for selected up- and downregulated genes (Figure 4). It was of particular interest to note that no compensatory changes in additional GST isoforms were identified in A2780/GSTP1 cells.

Pathway and process enrichment analysis was then used to identify common differentially regulated pathways or processes in A2780 and A2780/GSTP1 cells (Supplementary Table 2). Consistent with these predictions, the most significant differences in gene expression were seen for genes (e.g., N-cadherin (CDH2), versican (VCAN), L6 cell surface antigen (TM4SF1) and layilin (LAYN)) associated with cell invasion, migration, metastasis and the epithelial-mesenchymal transition. Consistent with known functions of the GSTs, several differentially regulated pathways and processes were associated with lipid metabolism and with the oxidative stress response, while additional interesting associations suggested altered cell cycle regulation and differences in apoptosis, cell invasion and migration. We therefore used quantitative cell growth, invasion and migration assays and FACS analysis to compare A2780 and A2780/ GSTP1 cell phenotypes. We did not observe significant differences in cell growth rates, where A2780 and A2780/GSTP1 cells had doubling times of 0.91 and 1.03 days, respectively $(P=0.462)$, or in cell cycle parameters, assessed by FACS analysis of propidium iodide-labelled untreated cells and stressed cells acutely treated with cisplatin (Figure 5A). In contrast, consistent with the gene expression and pathway/process differences described above, we found that both cell invasion (Figure 5B) and migration (Figure 5C) was significantly reduced in A2780/GSTP1 cells.

\section{DISCUSSION}

Conjugation of glutathione with platinum-based chemotherapy drugs is an important detoxification mechanism, which promotes drug clearance, limits the formation of DNA crosslinks and reduces toxicity (Peklak-Scott et al, 2008). It is therefore logical that the expression of glutathione-conjugating enzymes including GSTP1 is increased as an adaptive response in drug-resistant tumour cells (Black and Wolf, 1991; McLellan and Wolf, 1999) and that reduced GSTP1 activity may influence chemosensitivity. Several studies, however, have described increased GSTP1 expression in drug-resistant cell lines following exposure to drugs which are not detoxified by glutathione conjugation (Wang et al, 1989), or which are not GSTP1 substrates (Tew, 1994)_ a direct role for GSTP1 in platinum chemosensitivity therefore remains to be unequivocally established.

We have shown for the first time that stable deletion of GSTP1 in A2780 ovarian tumour cells significantly and selectively increases sensitivity to cisplatin and carboplatin, drugs routinely used to treat ovarian cancer, a notoriously drug-resistant and clinically intractable disease. Importantly, loss of GSTP1 expression in the cisplatin-resistant A2780 subline A2780DPP was toxic to the cells in the presence of cisplatin, consistent with an important catalytic role for GSTP1 in glutathione conjugation in the detoxification pathway of platinum drugs. Consistent with this hypothesis, we found significant differences in intracellular glutathione levels and in sensitivity to the GST substrate ethacrynic acid in GSTP1 null cells. Although the role of GSTP1 in ovarian 

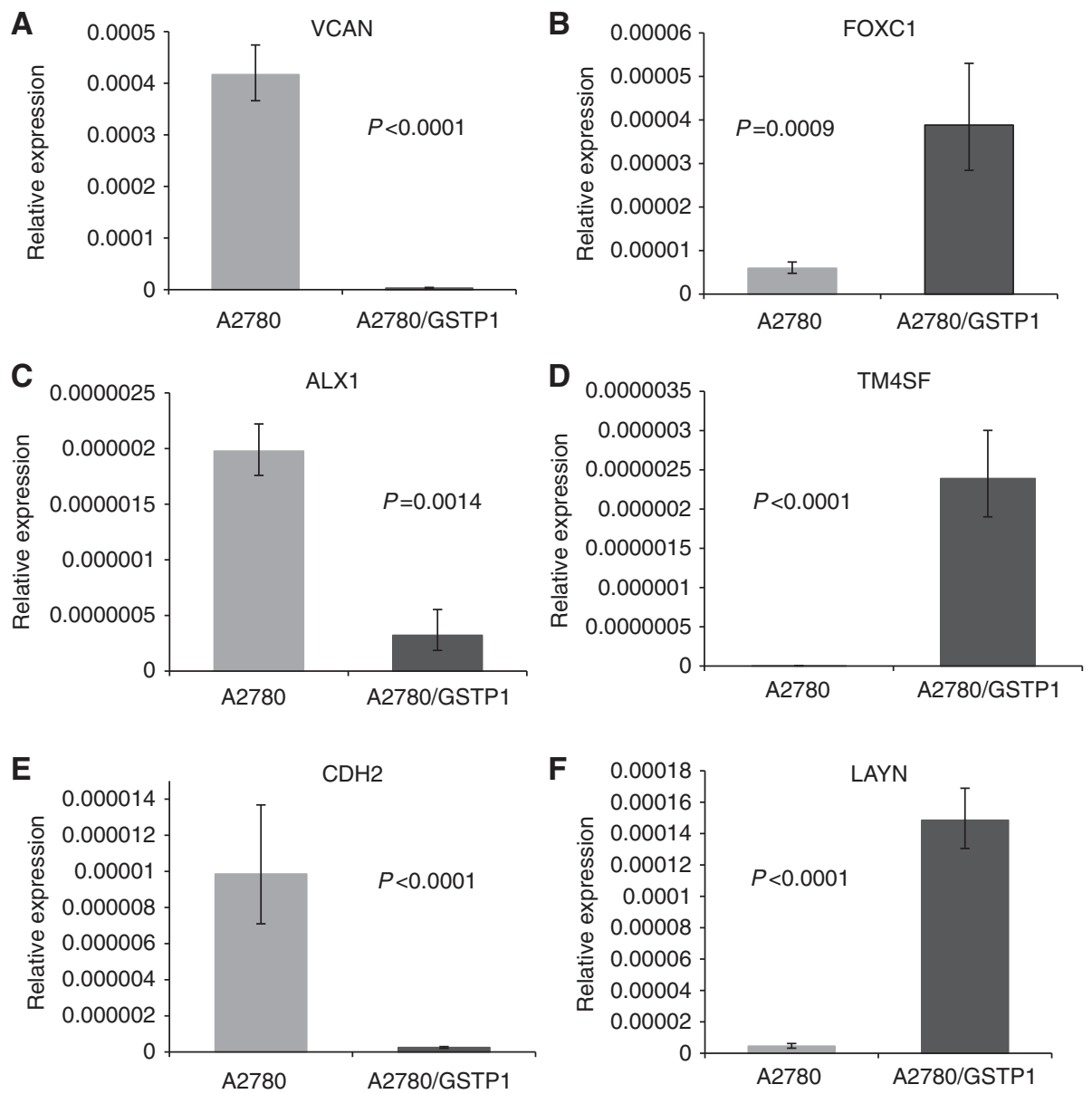

Figure 4. qRT-PCR analysis confirms gene expression changes predicted by lllumina Beadchip microarray analysis of A2780 and A2780/GSTP1 cells. qRT-PCR was performed, as described in Materials and Methods section, to confirm differential expression of selected genes predicted by comparative Illumina HT-12 Beadchip Array analysis to be differentially expressed in A2780 and A2780/GSTP1 cells-(A) VCAN, (B) FOXC1, (C) ALX1, (D) TM4SF, (E) CDH2 and (F) LAYN. All samples were analysed in triplicate; gene expression is illustrated relative to the expression of $18 \mathrm{~S}$ ribosomal RNA.

tumour chemosensitivity has not been studied, transient siRNAmediated GSTP1 knockdown in a diverse panel of leukaemia and lymphoma cell lines has recently also been reported to influence cisplatin sensitivity (Chen et al, 2013).

Glutathione $S$-transferase P1 has also been proposed to have a non-catalytic role in promoting cell proliferation by binding to and inhibiting JNK (Adler et al, 1999) - JNK activity is increased when GSTP1 activity is reduced, either by small molecule GSTP1 inhibitors or in GSTP1 null mice (Henderson et al, 1998). It is logical to propose, therefore, that stable GSTP1 deletion in A2780 ovarian tumour cells may result in JNK activation. Consistent with this hypothesis, interrogation of our gene expression microarray data sets revealed increased expression of several $J N K$ regulatory genes including the toxicity and JNK inducer TAJ (TNFRSF19, 8.33 -fold, adjusted $P$-value $1.25 \times 10^{-18}$, Supplementary Table 1 ), and JNK target genes including the p53-inducible proteins TP53I3 (PIG3, 5.02-fold, adjusted $P$-value $1.73 \times 10^{-16}$ ) and CDKN1A ( $p 21,4.87$-fold, adjusted $P$-value $9.62 \times 10^{-15}$ ) in GSTP1 knockdown cells. Although many of the genes up- and downregulated by GSTP1 deletion are associated with the RAS/MAPK pathway (Supplementary Table 1), we did not detect a significant difference in $R A S / M A P K$ pathway activation, using a quantitative RAF-1binding/Ras GTPase ELISA to assess pathway activation in GSTP1 knockdown cells (data not shown). In contrast, several differentially expressed genes (e.g., $\mathrm{CDH} 2$ ) and associated pathways and processes suggested that GSTP1 knockdown may significantly inhibit cell invasion and migration-these predictions were confirmed experimentally, and are consistent with the hypothesis that increased GSTP1 expression promotes neoplastic transformation and the development of drug resistance. We were therefore surprised to find that GSTP1 knockdown did not significantly influence cell growth rate or alter cell cycle progression in A2780 cells, although similar findings have been reported in a series of ovarian cancer cell lines made resistant to cisplatin, carboplatin and paclitaxel (Li et al, 2004), suggesting limitations of the use of immortalised cancer cell line models. Similarly, and consistent with a previous report of comparable GSTP1 expression in A2780 cells and the cisplatin-resistant derivatives C70 and C200 (Townsend et al, 2002), we did not detect a significant increase in GSTP1 expression in platinum-resistant A2780DPP cells. In contrast, increased GSTP1 expression has been described in many drugresistant cell lines (Kuroda et al, 1991; Kotoh et al, 1997; Tozawa et al, 2008; Yang et al, 2009), including ovarian tumour lines resistant to platinum drugs (Lewis et al, 1988; Parekh and Simpkins, 1996; Yanagie et al, 2009). Recent data from our own laboratory, where we see increased GSTP1 expression in a novel drug-resistant A2780 subline immediately following de novo platinum selection, further support the hypothesis that increased GSTP1 expression may not be maintained in long-term culture of immortalised tumour cells. In light of these concerns, we are currently extending our analysis to additional immortalised cell lines, with different histologies and genetic backgrounds and to primary cell lines derived from ascites from drug-sensitive and drug-resistant ovarian cancer patients. 
A

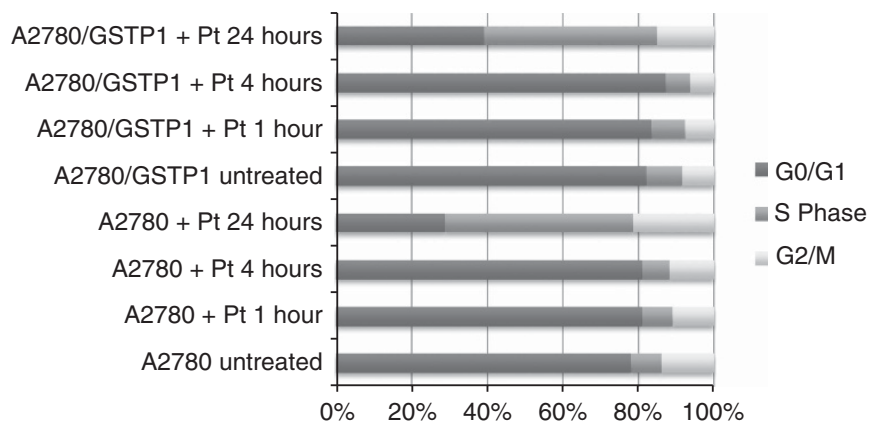

B

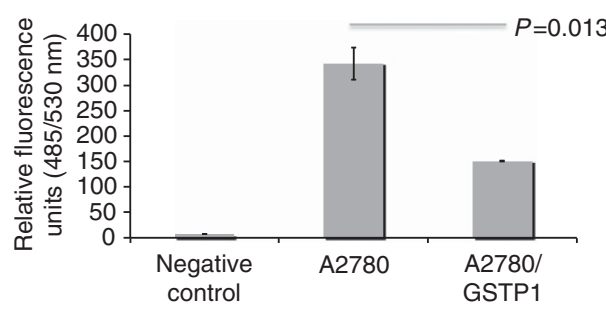

C

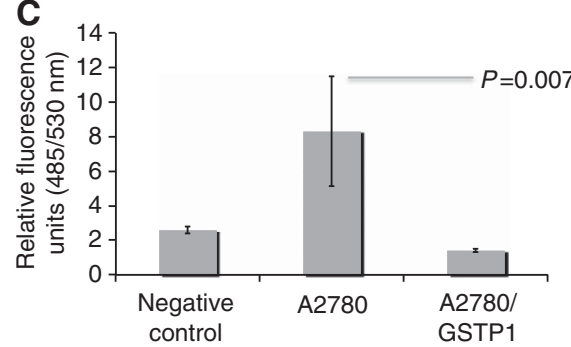

Figure 5. Phenotypic comparison of A2780 and A2780/GSTP1 knockdown cells. (A) FACS analysis of PI-labelled cells was used, as described in Materials and Methods section, to compare cell cycle progression of A2780 and A2780/GSTP1 cells, before and following cisplatin challenge. Each sample was analysed in triplicate-the relative proportions of cells in each phase of the cell cycle at each time point is illustrated. Boyden chamber-based (B) invasion (using cell culture media supplemented with 10\% FBS as chemoattractant) and (C) migration (ECMatrix) assays were then used to compare predicted phenotypes in negative (Latrunculin A-treated) controls, A2780 and A2780/GSTP1 cells as described in Materials and Methods section.

Glutathione $S$-transferase P1 expression in cancer patients may also be influenced by the presence of allelic variants-GSTP1 $\mathrm{Ile}_{105} \mathrm{Val}$ (rs1695) and GSTP1 Ala ${ }_{114} \mathrm{Val}$ (rs1138272), with homozygote rare allele frequencies of approximately $12 \%$ and $2 \%$ in the Caucasian population, respectively (Zimniak et al, 1994; Ali-Osman et al, 1997; Harries et al, 1997; Sachse et al, 2002). Unlike GSTM1 and GSTT1, however, where common polymorphisms result in complete gene deletions (Board, 1981), variant GSTP1 alleles differ from the consensus reference sequence by single aminoacid substitutions, resulting in less pronounced, less frequent and less well-characterised phenotypes (Peklak-Scott et al, 2008). In contrast, however, our recent gene expression profiling experiments in human ovarian tumours describe marked ( $>70$-fold) inter-tumour differences in GSTP1 expression, suggesting that individuality in glutathione-conjugating activity, although not genetically determined, could significantly influence response to platinum-based chemotherapy in ovarian cancer patients.

Studying the influence of inter-individual differences in GSTP1 expression on disease progression or chemotherapy response in ovarian cancer patients is challenging-the disease is frequently diagnosed at an advanced stage, limiting the availability of matched normal and tumour samples, and serial matched drugsensitive and drug-resistant tumour biopsies are rarely available. Increased GSTP1 expression in ovarian tumours $(n=41)$, relative to unmatched healthy ovarian samples $(n=12)$ and benign tumours $(n=25)$ has been described in a small Chinese study (Cheng et al, 2000) and, consistent with our findings, GSTP1 expression in ovarian cyst fluid has been correlated with higher relapse rates following platinum-based chemotherapy (Boss et al, 2001). In similar studies, GSTP1 expression in ovarian cyst fluid correlated both with serum CA125 levels and reduced patient survival (Kolwijck et al, 2009), while in a small series $(n=30)$ of matched first and second-look laparotomies, increased GSTP1 expression was associated with disease progression, assessed by both more frequent relapses and reduced survival (Surowiak et al, 2005).
Confirmation of a direct role for GSTP1 in chemotherapy response is important, not only in the prediction of response to platinum-based chemotherapy, but as a candidate response biomarker for new generation chemotherapy drugs, designed to exploit increased GSTP1 expression in tumours relative to surrounding normal tissues. For example, TLK-286 (Telcyta, canfosfamide) was identified as the lead candidate in a rationally designed series of selectively toxic glutathione analogues (Lyttle et al, 1994), which continues to be evaluated both as a single agent and in combination chemotherapy in phase II and III clinical trials in ovarian cancer and other solid tumours. TLK-286 is metabolically activated by GSTP1 and cytotoxicity has been correlated with GSTP1 expression (Rosario et al, 2000; Dourado et al, 2013). Increased GSTP1 expression in tumours and in drug-resistant cells is also the target of a new class of GST suicide inhibitors, including 7-nitro-2,1,3-benzoxadiazole (NBDHEX) (Ricci et al, 2005), which acts to induce apoptosis by promoting dissociation of the GSTP1/ JNK1 complex in leukaemia cell lines (Turella et al, 2005). Similar effects were recently observed in mesothelioma cell lines, where NBDHEX synergised with cisplatin (De Luca et al, 2013).

We have described marked inter-tumour differences in GSTP1 expression but, unlike fibroblast growth factor $(F G F)$ family genes, pre-treatment tumour GSTP1 expression was not influenced by tumour histology or associated with altered survival (Smith et al, 2012). Our study did not have sufficient power to perform a meaningful assessment of the potential role of GSTP1 in chemotherapy response, although we believe that lack of routine access to comparable clinical biopsy or tumour samples from ovarian cancer patients pre- and post-treatment may significantly limit tumour biomarker utility. It is interesting to note, however, that postchemotherapy GSTP1 expression was associated with progression-free survival in a small study ( $n=41$ patients) where pre- and postchemotherapy biopsies were available (Saip et al, 2005). We are therefore currently recruiting ovarian cancer patients to clinical studies in which we are collecting serial serum and ascites samples from matched drug-sensitive and drug-resistant patients for 
quantitative biomarker profiling. GSTP1 expression has previously been investigated by immunostaining in ovarian ascites samples, and shown to correlate with both primary tumour expression and cisplatin chemosensitivity (Kase et al, 1998). Our microarray data sets provide numerous examples of GSTP1-dependent gene expression changes, and may therefore allow us to identify additional biomarkers, which correlate with GSTP1 activity. Additional candidate GSTP1 biomarkers have recently identified in studies describing an inverse association between GSTP1 expression, chemosensitivity and expression of the regulatory microRNA miR-513a-3p in cisplatin-resistant A549 lung cancer cells (Zhang et al, 2012). Similarly, interleukin-6 (IL-6) production has been shown to be elevated in both serum and ascites samples from ovarian cancer patients and to be inversely associated with platinum chemosensitivity and survival (Scambia et al, 1995). Of obvious relevance to our findings, GSTP1 has recently been shown to be an IL-6 target gene (Wang et al, 2010), while inhibition of GSTP1 activity by an IL-6 or IL-6 receptor mAb correlates with increased platinum (and paclitaxel) sensitivity in renal cancer cells (Mizutani et al, 1995). It will therefore be of particular interest to compare GSTP1 and IL-6 levels in serum and ascites samples from drug-sensitive and drug-resistant ovarian cancer patients.

In summary, and consistent with the findings of a recent similar study in mesothelioma (Chen et al, 2014), we have shown that GSTP1 selectively influences sensitivity to cisplatin and carboplatin in ovarian tumour cells. Additional studies to evaluate the role of GSTP1 and co-regulated genes as clinical response biomarkers of disease progression and platinum chemosensitivity in ovarian cancer patients are underway in our laboratory.

\section{ACKNOWLEDGEMENTS}

We are grateful to the Genetics Core, Wellcome Trust Clinical Research Facility, University of Edinburgh for help with microarray analysis and to Dr Michael Boylan, Flow Cytometry Core Facility, University Dundee for FACS advice. We gratefully acknowledge funding from a Scottish Funding Council Strategic Research Development Grant, from Cancer Research UK (C4639/A10822) and from the Melville Trust for the Care and Cure of Cancer.

\section{REFERENCES}

Adler V, Yin Z, Fuchs SY, Benezra M, Rosario L, Tew KD, Pincus MR, Sardana M, Henderson CJ, Wolf CR, Davis RJ, Ronai Z (1999) Regulation of JNK signaling by GSTp. EMBO J 18(5): 1321-1334.

Ahokas JT, Davies C, Ravenscroft PJ, Emmerson BT (1984) Inhibition of soluble glutathione S-transferase by diuretic drugs. Biochem Pharmacol 33(12): 1929-1932.

Ali-Osman F, Akande O, Antoun G, Mao JX, Buolamwini J (1997) Molecular cloning, characterization, and expression in Escherichia coli of full-length cDNAs of three human glutathione S-transferase Pi gene variants. Evidence for differential catalytic activity of the encoded proteins. J Biol Chem 272(15): 10004-10012.

Anathy V, Roberson E, Cunniff B, Nolin JD, Hoffman S, Spiess P, Guala AS, Lahue KG, Goldman D, Flemer S, van der Vliet A, Heintz NH, Budd RC, Tew KD, Janssen-Heininger YM (2012) Oxidative processing of latent Fas in the endoplasmic reticulum controls the strength of apoptosis. Mol Cell Biol 32(17): 3464-3478.

Ban N, Takahashi Y, Takayama T, Kura T, Katahira T, Sakamaki S, Niitsu Y (1996) Transfection of glutathione S-transferase (GST)-pi antisense complementary DNA increases the sensitivity of a colon cancer cell line to adriamycin, cisplatin, melphalan, and etoposide. Cancer Res 56(15): $3577-3582$.

Behrens BC, Hamilton TC, Masuda H, Grotzinger KR, Whang-Peng J, Louie KG, Knutsen T, McKoy WM, Young RC, Ozols RF (1987) Characterization of a cis-diamminedichloroplatinum(II)-resistant human ovarian cancer cell line and its use in evaluation of platinum analogues. Cancer Res 47(2): 414-418.
Black SM, Beggs JD, Hayes JD, Bartoszek A, Muramatsu M, Sakai M, Wolf CR (1990) Expression of human glutathione S-transferases in Saccharomyces cerevisiae confers resistance to the anticancer drugs adriamycin and chlorambucil. Biochem J 268(2): 309-315.

Black SM, Wolf CR (1991) The role of glutathione-dependent enzymes in drug resistance. Pharmacol Ther 51(1): 139-154.

Board PG (1981) Biochemical genetics of glutathione-S-transferase in man. Am J Hum Genet 33(1): 36-43.

Boss EA, Peters WH, Roelofs HM, Boonstra H, Steegers EA, Massuger LF (2001) Glutathione S-transferases P1-1 and A1-1 in ovarian cyst fluids. Eur J Gynaecol Oncol 22(6): 427-432.

Chen J, Hurford M, Mekan S, Simpkins H (2013) Downregulation of glutathione transferase pi sensitizes lymphoma/leukaemia cells to platinum-based chemotherapy. Br J Haematol 162(1): 135-137.

Chen J, Solomides C, Simpkins H (2014) Sensitization of mesothelioma cells to platinum-based chemotherapy by GSTpi knockdown. Biochem Biophys Res Commun 447(1): 77-82.

Cheng G, Zhu H, Sun L (2000) [The expression of multiple drug resistance associated genes in ovarian cancer]. Zhonghua fu chan ke za zhi 35(2): 87-90.

De Luca A, Pellizzari Tregno F, Sau A, Pastore A, Palumbo C, Alama A, Cicconi R, Federici G, Caccuri AM (2013) Glutathione S-transferase P1-1 as a target for mesothelioma treatment. Cancer Sci 104(2): 223-230.

Dourado DF, Fernandes PA, Ramos MJ, Mannervik B (2013) Mechanism of glutathione transferase P1-1-catalyzed activation of the prodrug canfosfamide (TLK286, TELCYTA). Biochemistry 52(45): 8069-8078.

Eastman A (1987) The formation, isolation and characterization of DNA adducts produced by anticancer platinum complexes. Pharmacol Ther 34(2): 155-166.

Elsby R, Kitteringham NR, Goldring CE, Lovatt CA, Chamberlain M, Henderson CJ, Wolf CR, Park BK (2003) Increased constitutive c-Jun $\mathrm{N}$-terminal kinase signaling in mice lacking glutathione S-transferase Pi. J Biol Chem 278(25): 22243-22249.

Galluzzi L, Senovilla L, Vitale I, Michels J, Martins I, Kepp O, Castedo M, Kroemer G (2012) Molecular mechanisms of cisplatin resistance. Oncogene 31(15): 1869-1883.

Hagrman D, Goodisman J, Souid AK (2004) Kinetic study on the reactions of platinum drugs with glutathione. J Pharmacol Exp Ther 308(2): 658-666.

Harries LW, Stubbins MJ, Forman D, Howard GC, Wolf CR (1997) Identification of genetic polymorphisms at the glutathione S-transferase Pi locus and association with susceptibility to bladder, testicular and prostate cancer. Carcinogenesis 18(4): 641-644.

Hayes JD, Pulford DJ (1995) The glutathione S-transferase supergene family: regulation of GST and the contribution of the isoenzymes to cancer chemoprotection and drug resistance. Crit Rev Biochem Mol Biol 30(6): 445-600.

Henderson CJ, Smith AG, Ure J, Brown K, Bacon EJ, Wolf CR (1998) Increased skin tumorigenesis in mice lacking pi class glutathione S-transferases. Proc Natl Acad Sci USA 95(9): 5275-5280.

Ishimoto TM, Ali-Osman F (2002) Allelic variants of the human glutathione S-transferase P1 gene confer differential cytoprotection against anticancer agents in Escherichia coli. Pharmacogenetics 12(7): 543-553.

Kase H, Kodama S, Nagai E, Tanaka K (1998) Glutathione S-transferase pi immunostaining of cisplatin-resistant ovarian cancer cells in ascites. Acta Cytologica 42(6): 1397-1402.

Kolwijck E, Zusterzeel PL, Roelofs HM, Hendriks JC, Peters WH, Massuger LF (2009) GSTP1-1 in ovarian cyst fluid and disease outcome of patients with ovarian cancer. Cancer Epidemiol Biomarkers Prev 18(8): 2176-2181.

Konecny G, Crohns C, Pegram M, Felber M, Lude S, Kurbacher C, Cree IA, Hepp H, Untch M (2000) Correlation of drug response with the ATP tumorchemosensitivity assay in primary FIGO stage III ovarian cancer. Gynecol Oncol 77(2): 258-263.

Kotoh S, Naito S, Yokomizo A, Kohno K, Kuwano M, Kumazawa J (1997) Enhanced expression of gamma-glutamylcysteine synthetase and glutathione S-transferase genes in cisplatin-resistant bladder cancer cells with multidrug resistance phenotype. J Urol 157(3): 1054-1058.

Kristensen GB, Trope C (1997) Epithelial ovarian carcinoma. Lancet 349(9045): 113-117.

Kuroda H, Sugimoto T, Ueda K, Tsuchida S, Horii Y, Inazawa J, Sato K, Sawada T (1991) Different drug sensitivity in two neuroblastoma cell lines established from the same patient before and after chemotherapy. Int J Cancer 47(5): 732-737. 
Lewis AD, Hayes JD, Wolf CR (1988) Glutathione and glutathione-dependent enzymes in ovarian adenocarcinoma cell lines derived from a patient before and after the onset of drug resistance: intrinsic differences and cell cycle effects. Carcinogenesis 9(7): 1283-1287.

Li L, Luan Y, Wang G, Tang B, Li D, Zhang W, Li X, Zhao J, Ding H, Reed E, Li QQ (2004) Development and characterization of five cell models for chemoresistance studies of human ovarian carcinoma. Int $\mathrm{J} \mathrm{Mol} \mathrm{Med}$ 14(2): 257-264

Lyttle MH, Satyam A, Hocker MD, Bauer KE, Caldwell CG, Hui HC, Morgan AS, Mergia A, Kauvar LM (1994) Glutathione-S-transferase activates novel alkylating agents. J Med Chem 37(10): 1501-1507.

McLellan LI, Wolf CR (1999) Glutathione and glutathione-dependent enzymes in cancer drug resistance. Drug Resist Updates 2(3): 153-164.

Mizutani Y, Bonavida B, Koishihara Y, Akamatsu K, Ohsugi Y, Yoshida O (1995) Sensitization of human renal cell carcinoma cells to cisdiamminedichloroplatinum(II) by anti-interleukin 6 monoclonal antibody or anti-interleukin 6 receptor monoclonal antibody. Cancer Res 55(3): 590-596.

Mosmann T (1983) Rapid colorimetric assay for cellular growth and survival: application to proliferation and cytotoxicity assays. J Immunol Methods 65(1-2): 55-63.

Parekh H, Simpkins H (1996) Cross-resistance and collateral sensitivity to natural product drugs in cisplatin-sensitive and -resistant rat lymphoma and human ovarian carcinoma cells. Cancer Chemother Pharmacol 37(5): 457-462.

Peklak-Scott C, Smitherman PK, Townsend AJ, Morrow CS (2008) Role of glutathione S-transferase P1-1 in the cellular detoxification of cisplatin. Mol Cancer Ther 7(10): 3247-3255.

Ricci G, De Maria F, Antonini G, Turella P, Bullo A, Stella L, Filomeni G, Federici G, Caccuri AM (2005) 7-Nitro-2,1,3-benzoxadiazole derivatives, a new class of suicide inhibitors for glutathione S-transferases. Mechanism of action of potential anticancer drugs. J Biol Chem 280(28): 26397-26405.

Rosario LA, O'Brien ML, Henderson CJ, Wolf CR, Tew KD (2000) Cellular response to a glutathione S-transferase P1-1 activated prodrug. Mol Pharmacol 58(1): 167-174.

Sachse C, Smith G, Wilkie MJ, Barrett JH, Waxman R, Sullivan F, Forman D, Bishop DT, Wolf CR. Colorectal Cancer Study G (2002) A pharmacogenetic study to investigate the role of dietary carcinogens in the etiology of colorectal cancer. Carcinogenesis 23(11): 1839-1849.

Saip P, Tuzlali S, Demir K, Sakar B, Yavuz E, Berkman S, Bengisu E, Topuz E (2005) Value of glutathion-S transferase pi as a prognostic factor in epithelial ovarian carcinoma. Eur J Gynaecol Oncol 26(1): 90-94.

Satoh K, Kitahara A, Soma Y, Inaba Y, Hatayama I, Sato K (1985) Purification, induction, and distribution of placental glutathione transferase: a new marker enzyme for preneoplastic cells in the rat chemical hepatocarcinogenesis. Proc Natl Acad Sci USA 82(12): 3964-3968.

Scambia G, Testa U, Benedetti Panici P, Foti E, Martucci R, Gadducci A, Perillo A, Facchini V, Peschle C, Mancuso S (1995) Prognostic significance of interleukin 6 serum levels in patients with ovarian cancer. Br J Cancer 71(2): 354-356.

Shea TC, Kelley SL, Henner WD (1988) Identification of an anionic form of glutathione transferase present in many human tumors and human tumor cell lines. Cancer Res 48(3): 527-533.

Smith G, Ng MT, Shepherd L, Herrington CS, Gourley C, Ferguson MJ, Wolf CR (2012) Individuality in FGF1 expression significantly influences platinum resistance and progression-free survival in ovarian cancer. Br J Cancer 107(8): 1327-1336.

Smyth GK (2004) Linear models and empirical bayes methods for assessing differential expression in microarray experiments. Stat Appl Genet Mol Biol 3: Article3.
Sun KH, Chang KH, Clawson S, Ghosh S, Mirzaei H, Regnier F, Shah K (2011) Glutathione-S-transferase P1 is a critical regulator of Cdk5 kinase activity. J Neurochem 118(5): 902-914.

Surowiak P, Materna V, Kaplenko I, Spaczynski M, Dietel M, Lage H, Zabel M (2005) Augmented expression of metallothionein and glutathione S-transferase pi as unfavourable prognostic factors in cisplatin-treated ovarian cancer patients. Virchows Arch 447(3): 626-633.

Tew KD (1994) Glutathione-associated enzymes in anticancer drug resistance. Cancer Res 54(16): 4313-4320.

Townsend DM, Shen H, Staros AL, Gate L, Tew KD (2002) Efficacy of a glutathione S-transferase pi-activated prodrug in platinum-resistant ovarian cancer cells. Mol Cancer Ther 1(12): 1089-1095.

Tozawa K, Oshima T, Kobayashi T, Yamamoto N, Hayashi C, Matsumoto T, Miwa H (2008) Oxaliplatin in treatment of the cisplatin-resistant MKN45 cell line of gastric cancer. Anticancer Res 28(4B): 2087-2092.

Turella P, Cerella C, Filomeni G, Bullo A, De Maria F, Ghibelli L, Ciriolo MR, Cianfriglia M, Mattei M, Federici G, Ricci G, Caccuri AM (2005) Proapoptotic activity of new glutathione S-transferase inhibitors. Cancer Res 65(9): 3751-3761.

Vaughan S, Coward JI, Bast RC, Berchuck A, Berek JS, Brenton JD, Coukos G, Crum CC, Drapkin R, Etemadmoghadam D, Friedlander M, Gabra H, Kaye SB, Lord CJ, Lengyel E, Levine DA, McNeish IA, Menon U, Mills GB, Nephew KP, Oza AM, Sood AK, Stronach EA, Walczak H, Bowtell DD, Balkwill FR (2011) Rethinking ovarian cancer: recommendations for improving outcomes. Nat Rev Cancer 11(10): 719-725.

Wang Y, Niu XL, Qu Y, Wu J, Zhu YQ, Sun WJ, Li LZ (2010) Autocrine production of interleukin- 6 confers cisplatin and paclitaxel resistance in ovarian cancer cells. Cancer Lett 295(1): 110-123.

Wang YY, Teicher BA, Shea TC, Holden SA, Rosbe KW, al-Achi A, Henner WD (1989) Cross-resistance and glutathione-S-transferase-pi levels among four human melanoma cell lines selected for alkylating agent resistance. Cancer Res 49(22): 6185-6192.

Wu Y, Fan Y, Xue B, Luo L, Shen J, Zhang S, Jiang Y, Yin Z (2006) Human glutathione S-transferase P1-1 interacts with TRAF2 and regulates TRAF2-ASK1 signals. Oncogene 25(42): 5787-5800.

Yanagie H, Hisa T, Ogata A, Miyazaki A, Nonaka Y, Nishihira T, Osada I, Sairennji T, Sugiyama H, Furuya Y, Kidani Y, Takamoto S, Takahashi H, Eriguchi M (2009) Improvement of sensitivity to platinum compound with siRNA knockdown of upregulated genes in platinum complexresistant ovarian cancer cells in vitro. Biomed Pharmacother 63(8): $553-560$.

Yang JX, Luo Y, Qiu HM, Tang WX (2009) Characterization and resistance mechanisms of cisplatin-resistant human hepatocellular carcinoma cell line. Saudi Med J 30(1): 35-40.

Yin Z, Ivanov VN, Habelhah H, Tew K, Ronai Z (2000) Glutathione $\mathrm{S}$-transferase $\mathrm{p}$ elicits protection against $\mathrm{H} 2 \mathrm{O} 2$-induced cell death via coordinated regulation of stress kinases. Cancer Res 60(15): 4053-4057.

Zhang X, Zhu J, Xing R, Tie Y, Fu H, Zheng X, Yu B (2012) miR-513a-3p sensitizes human lung adenocarcinoma cells to chemotherapy by targeting GSTP1. Lung Cancer 77(3): 488-494.

Zimniak P, Nanduri B, Pikula S, Bandorowicz-Pikula J, Singhal SS, Srivastava SK, Awasthi S, Awasthi YC (1994) Naturally occurring human glutathione S-transferase GSTP1-1 isoforms with isoleucine and valine in position 104 differ in enzymic properties. Eur J Biochem 224(3): 893-899.

This work is published under the standard license to publish agreement. After 12 months the work will become freely available and the license terms will switch to a Creative Commons AttributionNonCommercial-Share Alike 3.0 Unported License.

Supplementary Information accompanies this paper on British Journal of Cancer website (http://www.nature.com/bjc) 